\title{
Delaying Retirement and Individual Account Finance of China's Basic Pension Insurance
}

\author{
Xiaohua Chen \\ *Corresponding Author \\ Xiaohua Chen \\ Article History \\ Received: 30.07 .2020 \\ Accepted: 07.08.2020 \\ Published: 13.08.2020
}

School of Insurance, Central University of Finance and Economics, Beijing 100081, China

\begin{abstract}
To actively respond to the payment crisis of China's basic pension insurance caused by the aging of the population, the Chinese government is actively formulating the policy of delaying retirement. This paper designs four types of delaying retirement policies that may be issued by the Chinese government, and explores the effect of the delaying retirement policies on the financial status of individual account of China's basic endowment insurance. We find that the delaying retirement policy is beneficial to the financial status of individual account in the early stage of the forecast, but it will worsen the financial situation of the individual account in the later period of the forecast. There is no significant difference in the effects of the delaying retirement policy under the four different schemes and different genders.
\end{abstract}

Keywords: Pension, delaying retirement, individual account, financial effect.

\section{INTRODUCTION}

The aging population has made governments around the world increasingly concerned about the payment crisis of basic pensions. At present, China's basic pension insurance has gradually shown a payment crisis in which pension income does not cover pension expenditure. According to the China Statistical Yearbook 2019, it can be seen that the basic pension insurance funds for urban employees in Liaoning, Heilongjiang, Hubei, and Qinghai provinces in 2018 have appeared that their pension income can not offset pension expenditure. With the deepening of the aging of population, more and more provinces in China will face the dilemma that the pension insurance contribution income is less than the pension expenditure, which will aggravate the basic pension payment crisis in China.

The financial sustainability of China's basic pension insurance and its payment dilemma has always been the research focus of domestic scholars. Many scholars (e.g., Yang and Shi [1]; Tian and Zhao [2]; Zhao et al., [3]; Chen and Yang [4]; Chen [5]; etc.) believed that the sustainability of China's basic pension insurance will face serious challenges, and there will be a large gap between pension income and pension expenditure. The individual account of basic pension insurance, established in the document of "Decision on Establishing a Unified Basic Pension System for Enterprise Employees', i.e. State Council Document 26 in 1997, is an important part of China's basic pension insurance system. Under individual account system, the more pension insurance premium the insured pay, the more pension they will get when they retire. Therefore, it can incentivize the insured persons to pay the pension insurance premiums more actively in order to increase their pension level at retirement. In view of the important role of individual account in improving the pension benefits of retirees, it is urgent to pay attention to the financial status of the account to ensure that the account can pay pensions to retirees in full and on time.

In order to actively respond to the aging population and ease the pressure on the payment of basic pension, the Chinese government is formulating the policy of delaying retirement and raising the legal retirement age of employees. Scholars hold two different views on whether the delaying retirement policy can really ease the pressure on pension payments. Some scholars believe that delaying retirement can relieve the payment pressure on pension fund and contribute to the sustainability of the fund (Cremer and Pestieau [6]; Karlstrom et al., [7]; Galasso [8]; Breyer and

Copyright @ 2020: This is an open-access article distributed under the terms of the Creative Commons Attribution license which permits unrestricted use, distribution, and reproduction in any medium for non commercial use (NonCommercial, or CC-BY-NC) provided the original author and source are credited. 
Hupfeld [9]; Tian and Zhao [2]; Ren et al., [10]; etc.). However, some scholars have questioned the effect of the delaying retirement policy, believing that the delaying retirement policy is difficult to alleviate the pension payment dilemma (Weller [11]; Miyazaki [12]; Yang [13]; etc.). What is the effect of delaying retirement policy on individual account of basic pension insurance? In order to improve the sustainable operation ability of individual account, it is necessary to study deeply and clarify the effect of delaying retirement policy on individual account of basic old-age insurance in China.

\section{Design of Delaying Retirement Schemes}

The Chinese government has not yet officially issued an official delaying retirement policy. Without losing generality, we design four types of delaying retirement policies to study the effects of delaying retirement policies on individual account of China's basic pension insurance.

The current retirement age in China is still the statutory retirement age standard formulated in 1978: the retirement age for male employees is 60 years old, and that for female employees is 55 years old. With reference to the experience of previous scholars on the design of China's delaying retirement policy, and combined with the actual situation of the current retirement age of Chinese employees, four types of delaying retirement policies are designed as follows.

The last year of the period to examine the effect of the delaying retirement policy is $T$, where $T=2095$. The retirement age of insured employees is $r$, and the starting year of delaying retirement policy is $t_{s}$. Suppose that both male and female employees start to postpone their retirement in $t_{s}$, and here $t_{s}=2022$. The target delaying retirement age for both male and female employees is 65 years old, that is, the delaying retirement age of male employees is raised from the current 60 years old to the target retirement age of 65 years old, and remains unchanged after 65 years old. The same is true to female employees, whose deferred retirement age has been raised from the current 55 year old to the target retirement age of 65 years old, and then remains unchanged at 65 years old. The retirement age of male and female employees is increased by $n / 12$ years old every year. When $n$ is equal to 3, 6, 9 and 12 months, four types of delaying retirement policies can be obtained, as shown in Figure-1.

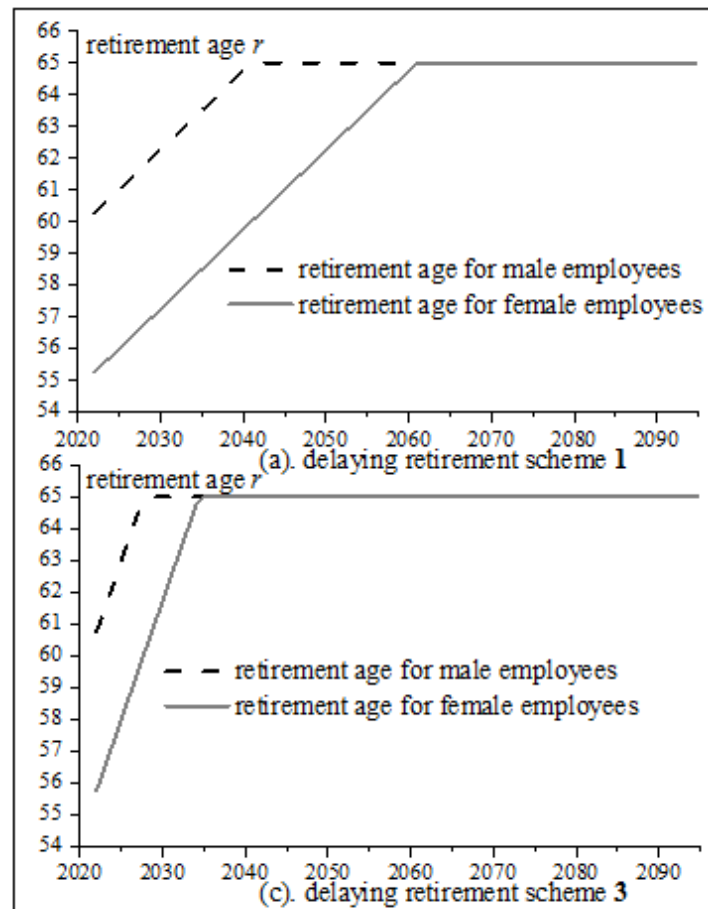

Fig-1: Four different delaying retirement schemes

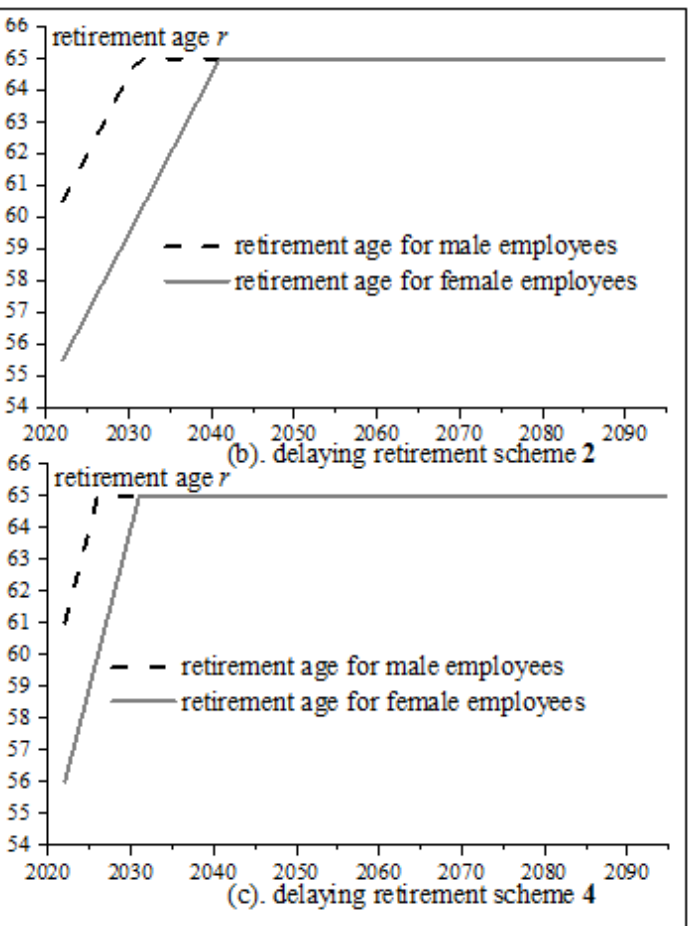

c). delaying retirement scheme 4

\section{The Model of Delaying Retirement and Individual Account Pension Incomes and Expenditures}

Model variables are set below. The age at which employees get their first job and participate in basic pension insurance is set to $e$, and the ultimate age is $\omega . L_{t, x}$ is the number of employees in the basic pension insurance of enterprise employees aged $x$ in year $t . \bar{S}_{t}$ is the weighted average wage of urban unit employees in year $t . S_{t, x}$ is the wage of the on-the-job employee at the age of $x$ in year $t$, and $s$ is the growth rate of seniority wage. The contribution rate of individual account is recorded as $c$, the $I_{t, x}$ is the pension from individual account received by retirees aged $x$ in year $t$. 
The $g_{t}$ and $j_{t}$ are wage growth rate and bookkeeping rate in year $t$ respectively. The $z$ is the starting year of the implementation of the document of "Decision on Establishing a Unified Basic Pension System for Enterprise Employees" (State Council Document 26 in 1997), i.e., $z=1997$. It is assumed that employees pay pension insurance premiums and retirees receive pensions at the end of each year.

\section{Pension Contributions of Individual Account}

The contribution incomes $C_{t}$ of the individual account for basic pension insurance is equal to the old-age insurance premiums paid by the insureds themselves. According to the regulations of the State Council Document 26 in 1997, and referring to the methods of Yang and Shi [1], and Chen and Yang [4], the formula $C_{t}$ is

$$
C_{t}=c \cdot \sum_{x=e}^{r-1} L_{t, x} \cdot S_{t-1, x-1}
$$

Where $S_{t, x}=(1+s) \cdot S_{t, x-1}=\cdots=(1+s)^{x-e} S_{t, e}$ and $S_{t, x}=\left(1+g_{t}\right) \cdot S_{t-1, x-1}$, the $S_{t, e}$ is the salary level of new entrants in year $t$. Thus, the $S_{t, x}$ can be calculated for each year of the forecast period.

\section{Pension Expenditures of Individual Account}

Based on the State Council Document 26 in 1997, the basic pension insurance for enterprise employees can be divided into "old-persons", "middle-persons" and "new-persons". The "old-persons" refer to the insured persons who have retired before the implementation of the document; the "middle-persons" refer to the insured persons who have participated in the work before the implementation of the document and retired after the implementation of the document; the "new-persons" refer to the insured persons who have participated in the work after the implementation of the document. Since the individual account system was established in 1997, the government does not need to pay for the pension expenses of the "old-persons" who have retired before 1997. The government only needs to pay the pension expenses for the "middle-persons" and the "new-persons".

\section{Pension Expenditures of the "Middle-Persons"}

The age range of the retired "middle-persons" is $[r, r+t-z-1]$ years old. When the retired "new-persons" appear, that is, $t \geq z+2+l_{m}$, the age range of the retired "middle-persons" becomes $\left[r+t-z-1-l_{m}, r+t-z-1\right]$ years old, where $l_{m}=r-e-1$. Thus, the age range can be recorded as $\left[\max \left(r, r+t-z-1-l_{m}\right), r+t-z-1\right]$ years old. The pension expenditures $P_{t}^{M}$ of the individual account for the retired "middle-persons" is:

$$
P_{t}^{M}=\sum_{x=\max \left(r, r+t-z-1-l_{m}\right)}^{r+t-z-1} L_{t, x} \cdot I_{t, x}
$$

Where the $m_{r}$ is the number of months of individual account pension that should be paid to retirees. According to the provisions of the State Council Document 26 in 1997 and referring to the methods of Yang and Shi [1], and Chen and Yang [4], then the expenditure $I_{t, x}$ is

$$
I_{t, x}=I_{t-(x-r), r}=\frac{12}{m_{r}} \times \sum_{k=\max \left(z, t-(x-r)-1-l_{m}\right)}^{t-(x-r)-1}\left[c_{k} S_{k-1, x+(k-1)-t} \cdot \prod_{h=k+1}^{t-(x-r)}\left(1+j_{h}\right)\right]
$$

\section{Pension Expenditures of the "New-Persons"}

The age range of the retired "new-persons" is $\left[r, r+t-z-1-l_{m}-1\right]$ years old, which is $[r, t-z+e-1]$ years old. As the years go on, the "new-persons" will constantly replace the "middle-persons". When $t \geq z-e+\omega+1$, all the retirees are "new-persons", and the "middle-persons" has disappeared. The pension expenditures $P_{t}^{N}$ of the individual account for the retired "new -persons" is:

$$
P_{t}^{N}=\sum_{x=r}^{t-z+e-1} L_{t, x} \cdot I_{t, x}
$$

Where the $I_{t, x}$ are consistent with the corresponding formula (3) of pension expenditures for "middle-persons".

\section{Total Pension Expenditures of Individual Account}

The basic pension expenditures of individual account for enterprise retirees are equal to the sum of basic pension expenditures of individual account for "middle-persons" and "new-persons": $P_{t}=P_{t}^{M}+P_{t}^{N}$. 
In summary, delaying retirement $r$ will not only affect the pension contribution incomes $C_{t}$ of the individual account, but also affect the pension expenditures $P_{t}$ of individual account. Therefore, the effect of delaying retirement on the financial status of individual account pension is uncertain, and in-depth simulation is needed to investigate the specific effect of delaying retirement policy on individual account.

\section{Estimation of Model Parameters}

\section{Forecast of China's Future Population Structure}

Using the cohort element method to predict China's future population structure, the required parameters are the initial population distribution, the fertility rate of women of childbearing age in each year of the prediction period, the sex ratio of newborns in each year of the prediction period, and the mortality rate during the prediction period. These parameters are estimated in the following ways.

According to the China Population and Employment Statistical Yearbook 2019, the population distribution by age and gender in 2018 is divided by the corresponding sampling ratio, and the result is taken as the initial population distribution. According to the China Population and Employment Statistical Yearbook in 2001-2019, the average fertility rate $\left(F R_{t, x}\right)$ of women of childbearing age in urban areas from 2000 to 2018 can be obtained, and the total fertility rate for these years is $T F R_{t}=\sum_{x=15}^{49} F R_{t, x}$. Then, divide the $F R_{t, x}$ by the $T F R_{t}$ to get the standardized fertility coefficient $h_{t, x}$ for these 19 years, and take their mean value $\bar{h}_{x}$ as the standardized fertility coefficient for each year during the forecast period. With reference to the forecast result of total fertility rate by the United Nations Population Division in China, China's future total fertility rate is set to 1.69 and remains unchanged. Then, the fertility rate $F R_{t, x}$ of women of childbearing age in each year of the forecast period can be calculated by $T F R_{t} \cdot \bar{h}_{x}$. In the prediction period, The $S R B_{t}$ of the sex ratio of newborns in each year in China refers to the intermediate program prediction results made by the United Nations Population Division in 2019. Zhai et al., [14] believed that the PADIS-INT software has a good forecasting effect on population structure, and its forecasting level has reached or even exceeded the international mainstream population forecasting software. Therefore, the mortality rate $q_{t, x}$ during the prediction period comes from the "Far East" life table model of PADIS-INT software, one of the mainstream international population prediction softwares. Finally, combining the above parameters and programming calculations based on the principle of the cohort element method, the future distribution structure of the age-sex population in China can be obtained.

\section{Estimation of Insured Persons}

The method of estimating the insured persons in the basic pension insurance for enterprise employees is as follows, and the cohort element method is also used to predict the number $\left(L_{t, x}\right)$ of insured persons.

The age-gender population structure of the insured persons in year $t$ consists of the newly recruited population ( $x=e$ years old) and the population of other ages $(x \geq e+1$ years old). The number of new ( $x=e$ years old) insured persons each year is equal to the population of the corresponding age in the future population structure of China multiplied by the urbanization rate, labor participation rate, pension insurance coverage rate, and the proportion of the insureds number of enterprise employees to the insureds number of urban employees. The number of insured persons of other ages $(x \geq e+1$ years) in each year can be obtained by multiplying the age-gender population of the insured persons in the previous year by the corresponding survival probability $\left(1-q_{t, x}\right)$.

The estimation of the initial distribution of the insured persons in the basic pension insurance for enterprise employees in China. According to the China Labor Statistics Yearbook 2019, the number of insured employees and the number of insured retirees in 2018 were 26.026 million and 99.805 million respectively. According to the China population and Employment Statistical Yearbook 2019, we can see the distribution of the population by age and gender in the cities and towns in 2018. By dividing it by the corresponding sampling ratio, we can get the actual population structure by age and gender in the cities and towns in 2018. Assuming that the age-gender structure of the number of insured employees and the number of insured retirees of enterprise employees nationwide is consistent with the actual population structure by age and gender in the cities and towns in 2018 , then the number of age-gender insured persons by the national enterprise employee basic pension insurance in 2018 can be calculated.

Estimation of labor participation rate, the urbanization rate, pension insurance coverage rate, and the proportion of the insureds number of enterprise employees to the insureds number of urban employees. From the China Population and Employment Statistical Yearbook 2019, it can be seen that the average registered unemployment rates in urban areas from 2000 to 2018 was $4.01 \%$, so the labor participation rate was $95.99 \%$. The model of ARIMA $(1,1,0)$ is used to fit the urbanization rate sample datas onto 1980 to 2018 from China Statistical Yearbook 2019. Wang and Ge [15] assumed that the upper limit of China's urbanization rate is $80 \%$, so when the forecast results exceed $80 \%, 80 \%$ is taken as the 
urbanization rate in that year. With reference to Yang and Liao [16], the pension insurance coverage rate will increase by one percentage point from $85 \%$ in 2015 to $95 \%$ in 2025, and will remain unchanged in subsequent years. According to the China Human Resources and Social Security Yearbook 2019, it is known that the proportion of the insureds number of enterprise employees to the insureds number of urban employees in 2018 was $88.04 \%$, which was taken as the value of this proportion in each year of the forecast period.

\section{Other Qarameters}

The State Council Document 38 in 2005 of "Decision on Improving the Basic Pension System for Urban Employees" stipulated that the individual contribution rate $c$ is $8 \%$. The age $(e)$ for employees to get their first job and participate in the basic old-age insurance is set at 22. The ultimate age $\omega$ of the insured person is set to 100 years old. With reference to Yang and Shi [1], the growth rate of seniority wage $(s)$ is $1.363 \%$. Taking the salary of new recruits with higher vocational education as the average wage level of new recruits in enterprises across the country, the 2018 national graduate salary survey report released by China salary network showed that the average annual income of graduates of higher vocational colleges in 2018 was 52512 yuan, which is taken as the average salary of new recruits.

With reference to the method of Yang and Shi [1], the future salary growth rate and bookkeeping rate of China can be set. The salary growth rate will be $7.7 \%$ from 2019 to $2020,6.6 \%$ from 2021 to 2025 and $5.7 \%$ from 2026 to 2030, and keep $4.8 \%$ unchanged in other years. The bookkeeping rate is set at $3.27 \%$ in 2015 and before, and $7.83 \%$ in 2016 and later. According to the State Council Document 38 in 2005, the number of months $m_{r}$ corresponding to the retirement age $r$ can be obtained. When implementing the delaying retirement policy, if the retirement age $r$ is a noninteger, then the number of months corresponding to the integer part of the retirement age $r$ is taken as the $m_{r}$ of the noninteger $r$.

\section{Analysis of the Effect of Delaying Retirement Policy}

Referring to the methods of previous studies (e.g., Yang and Shi [1]; Zhang et al., [17]; Chen et al., [18]; etc.), we select the current balance of pension $\left(B_{t}\right)$ to measure the financial status of individual account of basic pension in China. The balance $B_{t}$ is defined as contribution incomes of individual account $C_{t}$ - pension expenditures of individual account $P_{t}$.

The effect of the delaying retirement policy on the individual account can be expressed as the change of the balance $\left(\Delta B_{t}\right)$ during the forecast period. $\Delta B_{t}=B_{t}^{\text {delay }}-B_{t}^{O}$. The $B_{t}^{\text {delay }}$ means the balance after considering the policy of delaying retirement. The $B_{t}^{O}$ refers to the balance without considering the delaying retirement policy (i.e., the retirement age of male and female employees are still 60 and 55 years old). Based on the model built in Section 3, using MATLAB to program, combined with the above parameters, the effect of the delaying retirement policy on of individual account of basic pension insurance in China can be obtained, as shown in Figure-2.

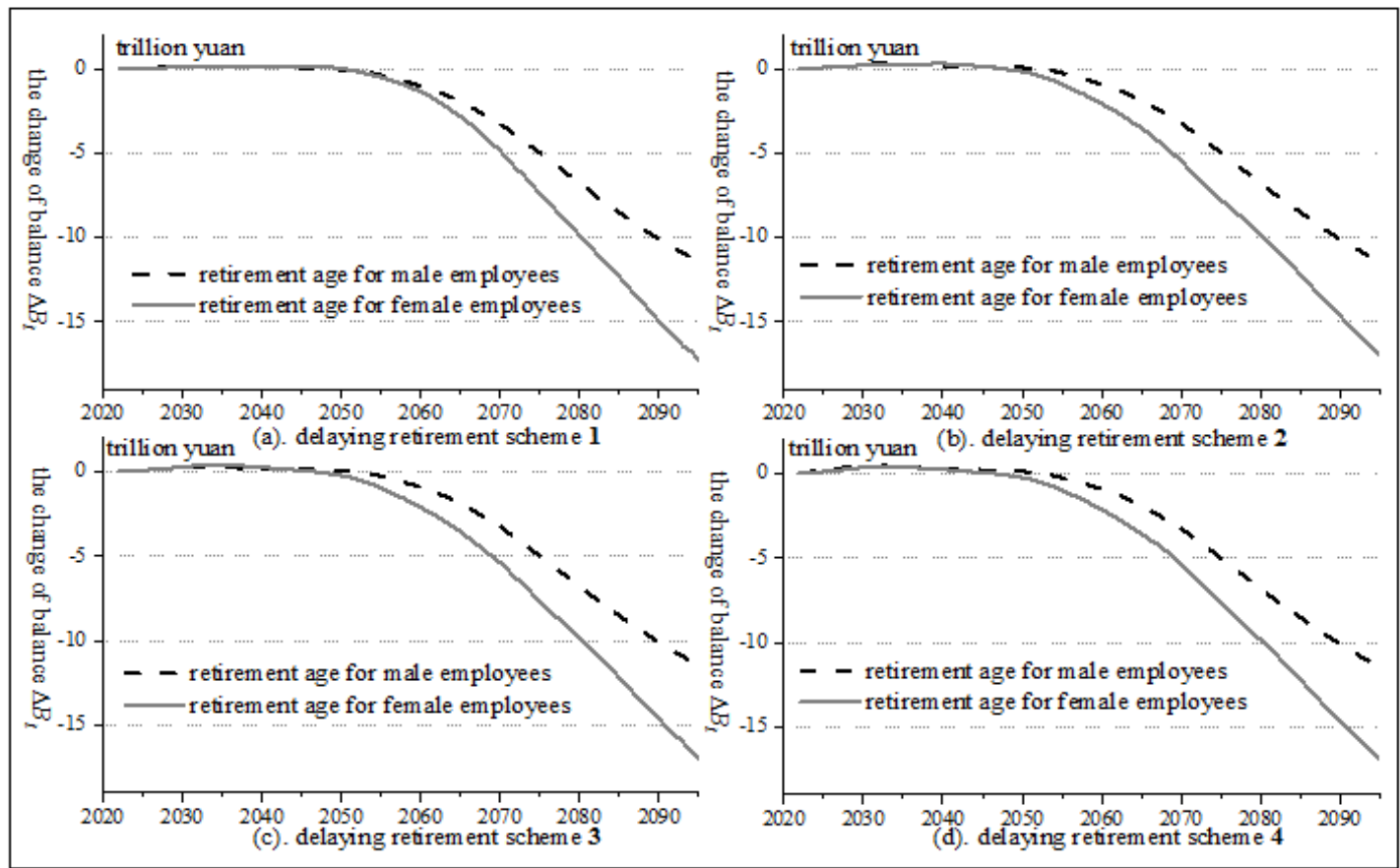

Fig-2: Effects of four types of delaying retirement policies 
It can be seen that in the whole forecast period [2022, 2095], the effect of the delaying retirement plan for the individual account of China's basic pension insurance is: in the early stage of the forecast, it is beneficial to the increase of the individual account balance, i.e., $\Delta B_{t} \geq 0$; this beneficial effect is gradually weakening, until the later period of the forecast, the delaying retirement scheme will have adverse effect, i.e., $\Delta B_{t}<0$.

The effects of the four types of delaying retirement policies on balance of individual account are basically the same, and there is no significant difference between the four different schemes. Their effects are that they will help to reduce the payment pressure on individual account in the early stage of the forecast, but will increase the payment pressure on individual account in the later stage of the forecast. In addition, gender-specific employees (i.e., male and female employees) have basically the same effect on the financial status of individual account in the four different schemes.

In summary, the effect of the delaying retirement policy on individual account of China's basic pension insurance is relatively clear. (1) It is conducive to the financial status of individual account in the early stage of forecasting, but it is not conducive to the financial status of individual account in the later stage of forecasting. (2) The effect of delaying retirement policy is basically the same under the four different schemes, and there is no significant difference among these schemes; the effect of the policy on the employees of different genders is also basically the same, and there is also no significant difference between them.

\section{ReSEARCH CONCLUSIONS}

This paper designs four types of delaying retirement policies that may be issued by the Chinese government in the future, and explores the effect of delaying retirement policies on the financial status of individual account of basic pension insurance in China. Based on the document of "Decision on Establishing a Unified Basic Pension System for Enterprise Employees" (the State Council Document 26 in 1997), and referring to the experience of previous studies (e.g., Yang and Shi [1]; Chen and Yang [4]; Chen et al., [18]), the model of delaying retirement and individual account pension incomes and expenditures can be constructed. The related parameters of the model are estimated, and the effects of delaying retirement policies are simulated by using MATLAB software. This research finds that the delaying retirement policy is beneficial to the financial status of individual account in the early stage of forecasting, but it is not beneficial to the financial status of individual account in the later stage of forecasting. There is no significant difference in the effects of delaying retirement policies under different schemes and different genders. Since the delaying retirement policy has both positive and negative impacts on individual account of China's basic pension insurance, the Chinese government should formulate the more reasonable delaying retirement policy to improve the sustainable operation ability of individual account of basic pension insurance in China.

\section{REFERENCES}

1. Yang, Z., \& Shi, C. (2016). Financial burden of pension in the pooling account of urban enterprise workers in China. Economic Science, 2:42-52.

2. Tian, Y., \& Zhao, X. (2016). Stochastic Forecast of the Financial Sustainability of Basic Pension in China. Sustainability, 8(1).

3. Zhao, Y., Bai, M., Feng, P., \& Zhu, M. (2018). Stochastic Assessments of Urban Employees' Pension Plan of China. Sustainability, 10(4).

4. Chen, X., \& Yang, Z. (2019). Stochastically Assessing the Financial Sustainability of Individual Accounts in the Urban Enterprise Employees' Pension Plan in China. Sustainability, 11(13).

5. Chen, X. (2019). Application of Several Classical Sorting Algorithms in Early Warning of Payment Risk of Basic Endowment Insurance Fund in China, South Asian Research Journal of Business and Management, 1(3):155-160.

6. Cremer, H., \& Pestieau, P. (2003). The double dividend of postponing retirement. International Tax and Public Finance, 10(4):419-434.

7. Karlstrom, A., Palme, M., \& Svensson, I. (2004). A dynamic programming approach to model the retirement behaviour of blue- collar workers in Sweden. Journal of Applied Econometrics, 19(6):795-807.

8. Galasso, V. (2008). Postponing retirement: the political effect of aging. Journal of Public Economics, 92(10):21572169.

9. Breyer, F., \& Hupfeld, S. (2010). On the Fairness of Early-Retirement Provisions. German Economic Review, 11(1):60-77.

10. Ren, X., Xi, H., Zhai, S., \& Zhou, M. (2019). Research on the Accumulation Effect of Pension Income and Payments Caused by Progressive Retirement Age Postponement Policy in China. Journal of Aging \& Social Policy, 31(2):155-169.

11. Weller, C. E. (2002). Don't Raise the Retirement Age. Challenge, 45(1):75-87.

12. Miyazaki, K. (2014). The effects of the raising-the-official-pension-age policy in an overlapping generations economy. Economics Letters, 123(3):329-332. 
13. Yang, H. (2019). Overlapping generations, population policy adjustment and economic growth. Economic Science, $3: 30-40$.

14. Zhai, Z., Li, L., \& Chen, J. (2017). Applications of Population Projection in the PADIS-INT: Comparative Study on MORTPAK, Spectrum and PADIS-INT. Population Research, 6:84-97.

15. Wang, J., \& Ge, Y. (2016). Population trends in China under the universal two-child policy. Population Research, 40(6):3-21.

16. Yang. Z., \& Liao, P. (2019). Actuarial Report on Basic Old-Age Insurance for Employees of Chinese Enterprises. Beijing, China: China Labor and Social Security Press, 215-264.

17. Zhang, X., Zeng, Y., Shi, C., \& Liu, T. (2018). Fiscal responsibility assessment of basic pension insurance for urban employees from a sustainable perspective-re-examination on the effect of universal two-child policy and delaying retirement policy. Public Finance Research, 12:97-113.

18. Chen, X., Zhong, S., \& Qi, T. (2020). Delaying Retirement and China's Pension Payment Dilemma: Based on a General Analysis Framework. IEEE Access, 8:126559-126572. 